\title{
Responding to Children When Their Parents are Incarcerated: Exploring the Responses in Victoria and New South Wales, Australia
}

\author{
Catherine Flynn, Tess Bartlett, Paula Fernandez \\ Arias, Phillipa Evans and Alannah Burgess*
}

There is considerable research conducted over the past 50 years which describes the impact on children of parental incarceration. Research has also focused on describing the care arrangements of such children. Yet there has been no specific examination of the trajectory of care for these children, the processes surrounding this care, or its resultant quality.

This article reports the findings of an ARC funded study examining care planning processes in Victoria and New South Wales for these children. We concentrate in this paper on a subset of data from 124 professional stakeholders, who commented on their experiences of responding to children, in the context of their organisational remit, processes and expectations. Findings indicate that children of prisoners are largely invisible in adult organisations and that there are typically poor or poorly understood interagency protocols to respond to these children. Respondents report relying on informal information, networks and resources and working outside of their role to meet the needs of children. Clear suggestions are made for improvements, including developing child-sensitive services; a child-focused approach and clearer protocols and guidelines for working with others.

\section{INTRODUCTION}

\section{A Imprisoning Adults = Imprisoning Parents}

The current growth in incarceration in Australia ${ }^{1}$ and similar patterns in other western countries, ${ }^{2}$ unsurprisingly has had flow-on effects to families. It is estimated that around 5\% of children in Australia will

\footnotetext{
* $\quad$ Feedback on earlier drafts of this paper was gratefully received by the authors from Victoria Police.

1 Australian Bureau of Statistics, Prisoners in Australia 2012, 4517.0. (ABS, 2013) <http:/www.abs.gov.au/ausstats/abs@.nsf/Products/6DBFA1B30E0FF7D9CA25 7B3C000DC7AF?opendocument>.

2 Ministry of Justice, Offender Management Statistics Quarterly Bulletin October to December 2011, England and Wales (Ministry of Justice, 2012); Australian Bureau of Statistics, above n 1.
} 
experience parental incarceration in their lifetime. ${ }^{3}$ In a recent survey by the Australian Institute of Health and Welfare some $28 \%$ of prisoners described having at least one child. ${ }^{4}$ However, accurate numbers remain unclear, including how many of these parents are direct carers. There are limited official data gathered on either the parenting status of individuals entering prison, or the status or whereabouts of any of their children. In some jurisdictions, prisons do seek information about children, but this is not widespread, nor is the information gathered or used systematically. This is not a new problem: since the 1960s there has been acknowledgement and concern about the impact on families when a family member, particularly a parent, is imprisoned. ${ }^{5}$ Research since then has tended to coalesce around three core areas:

1. Investigating intergenerational links in offending behaviour;

2. Describing, in broad terms the 'impact' on children of parental incarceration - focusing on behaviour and emotional impact; and

3. Describing who cares for children.

It is in this latter area where clear gender differences have been highlighted. Nearly two decades ago, Johnston ${ }^{6}$ drew attention to the fact that when fathers are incarcerated, the vast majority of children remain in their family home, cared for by their mother, whereas, when mothers are sent to prison, more commonly children require alternative arrangements. This pattern has been shown to hold in the years subsequent. ${ }^{7}$ It is important to note, however, that most research has tended to look at mothers separately or 'parents' broadly and that there has been limited focus on 'carers' - irrespective of gender.

In relation to the general impact of parental imprisonment on children, there have been considerable methodological challenges to building coherent knowledge in this area. Research has typically used small nonrepresentative samples, drawn on varied definitions of parents, relied on cross-sectional 'snap-shot' surveys, and rarely involved children. ${ }^{8}$ Despite this, the findings have shown considerable consistency and the impact on families of parental imprisonment has been demonstrated to

3 Susan Dennison, Anna Stewart and Kate Freiberg, 'A Prevalence Study of Children with Imprisoned Fathers: Annual and Lifetime Estimates' (2013) 48(3) Australian Journal of Social Issues 339; Simon Quilty, 'The Magnitude of Experience of Parental Incarceration in Australia'. Letter to the Editor (2005) 12 Psychiatry, Psychology and Law 256.

4 Australian Institute of Health and Welfare, The Health of Australia's Prisoners 2012 (AIHW, 2013).

5 See Phyllis Jo Baunach, Mothers in Prison (Transaction Books, 1985); K Brown, 'No-one's Ever Asked Me' Young People with a Prisoner in the Family (Action for Prisoners' Families, 2001).

6 D Johnston, 'The Care and Placement of Prisoners' Children' in K Gabel and D Johnston (eds), Children of Incarcerated Parents (Lexington Books, 1995) 103.

7 Lauren E Glaze and Laura M Maruschak, Parents in Prison and Their Minor Children (Bureau of Justice Statistics, 2008).

8 C Flynn, Waiting for Mum: The Impact of Maternal Incarceration on Adolescent Children [PhD Thesis] (Monash University, 2008). 
be wide-ranging. Practically, there are increased financial pressures, ${ }^{9}$ resulting in problems such as debt and problems with maintaining stable housing. Socially, stigma and isolation are key concerns, ${ }^{10}$ while psychologically, a range of strong emotions such as grief and loss, depression and shame are also common. ${ }^{11}$ Murray argues, ${ }^{12}$ however, that the extent to which these become problematic is likely to be mediated by other factors occurring pre-, during and post-imprisonment. Kruttschnitt ${ }^{13}$ also highlights the differential effects of parental incarceration, and makes a clear argument for a focus on the factors responsible for these variations, including external or systemic factors. She asks that we consider not just who is affected, but the processes which have an impact on outcomes.

In recent years, research in this area has taken on a more applied orientation, seeking to move beyond describing the impact of parental incarceration, to consider, for example, how to support these children and ensure better outcomes. Findings from UK research indicate that while children of offenders are significantly more disadvantaged across multiple life domains than their peers, the current system provides neither coherent support nor continuity of care; services are essentially fragmented. ${ }^{14}$ The authors' conclusions indicate that formulating effective responses requires a paradigm shift, to 'think family'. ${ }^{15}$ They argue that as a key transition point within the criminal justice system, parental imprisonment should be used to trigger a formal response to their children of assessment and intervention. They further argue that attention also needs to be broader: on working towards collaboration between services for children and adults. It is clear from this study that some of the factors which may 'make a difference' include the orientation of the service system (adult vs child), as well as a measure of assertive outreach and appropriate timing of responses.

\section{B 'Joining up’ Adult and Child Systems}

The criminal justice system is not the only adult-focused service system which is being challenged to see adult clients as parents. In Australia,

$9 \quad$ See Joyce A Arditti, Jennifer Lambert-Shute and Karen Joest, 'Saturday Morning at the Jail: Implications of Incarceration for Families and Children' (2003) 52(3) Family Relations 195; Rose Smith, R Grimshaw, R Romeo and M Knapp, Poverty and Disadvantage among Prisoners' Families (Joseph Rowntree Foundation, 2007).

10 Brown, above $\mathrm{n} 5$.

11 Flynn, above $\mathrm{n} 8$.

122005 cited in Alannah Burgess and Catherine Flynn, 'Supporting Imprisoned Mothers and Their Children: A Call for Evidence' (2013) 60(1) Probation Journal 73.

13 Candace Kruttschnitt, 'Is the Devil in the Details? Crafting Policy to Mitigate the Collateral Consequences of Parental Incarceration' (2011) 10(3) American Society of Criminology 829.

14 A Burns, V Brandon, K Oakes, D Olopade and S Krikorian, 'Children of Offenders Review' (National Offender Management Service and Department for Children Schools and Families, 2007). Ibid, 17. 
changes in adult mental health services have been encouraged by research which drew attention to children, ${ }^{16}$ and by subsequent advocacy groups such as Children of Parents with a Mental Illness (COPMI), utilising approaches such as a service development strategy for families where a parent has a mental illness (FaPMI). ${ }^{17}$ The Alcohol and Drug Sector has also brought attention to children of adult clients in both research ${ }^{18}$ and the implementation of family-focused training for Alcohol and Other Drug (AOD) workers. ${ }^{19}$ Addressing concerns in the health sector, St Vincent's Hospital, Melbourne, released a training DVD What about the children? Keeping children safe when your patient is a parent. ${ }^{20}$ It is noted in the resource that when dealing with adults in the health system, information about children is not routinely collected or recorded and suggestions are made for clear procedures and resources for hospital staff to address this. It concludes by stating that in order to improve responses to children who may be vulnerable, adult services need to: ask about children; listen to parents; record the information; and share the information appropriately. ${ }^{21}$ It is clear that a range of adult-focused services have been, and continue to be, challenged to acknowledge children and respond to them adequately. In both Victoria and NSW, where the current study is being conducted, there have been attempts to bring together key decision-makers to better coordinate cross-government policies and programs which impact on children and young people. ${ }^{22}$ Both states also have a children's commissioner. While minor mention is made in places of children of prisoners, to date, however, there has been no decisive action taken regarding this group.

The specific challenges posed by parental incarceration have been acknowledged and highlighted by Abram and Linhorst. ${ }^{23}$ Their research indicated that "parental incarceration tends to draw children of prisoners,

16 Vicki Cowling, 'Meeting the Support Needs of Families with Dependent Children Where the Parent Has a Mental Illness' (1996) 45 Family Matters 22.

17 The Bouverie Centre, FaPMI Service Development Strategy (2011) $<$ http://www.bouverie.org.au/programs/mental-health-team/fapmi/fapmiservice-development-strategy>.

18 Odyssey Institute of Studies, The Nobody's Clients Project: Identifying and Addressing the Needs of Children with Substance Dependent Parents (Odyssey House Victoria, 2004).

19 Dorothy Scott 'Think Child, Think Family' (2009) 81 Family Matters 37.

20 St Vincents Hospital, What About the Children? Keeping Children Safe When Your Patient Is a Parent (St Vincent's Hospital, 2013).

21 Ibid.

22 See, for example, Department of Education and Early Childhood Development, Children's Services Coordination Board (2014) <http://www.education.vic.gov. au/about/department/structure/pages/coordboard.aspx $>$; Department of Premier and Cabinet, Community Sector Reform Council (2014) <http://www.dpc.vic.gov. au/index.php/featured/community-sector-reform-council>; NSW Government, Keep them Safe A shared Approach to Child Wellbeing (2014) <http://www. keepthemsafe.nsw.gov.au/>.

23 Faye Y Abram and Donald Linhorst, 'A Process Evaluation of Collaborative Planning for Children of Prisoners' (2007) 32(1) Administration in Social Work 39. 
their caregivers, and parents into several systems that historically have not shared target populations, had common interacting problems, or worked together' ${ }^{24}$ This can be seen quite simply: children's services typically do not ask about parental incarceration, and adult services do not, as a matter of course, ask about children. That small exploratory study in a US jurisdiction suggests that creating linkages between statutory and non-government services, and between prison and community based services, is essential to ensuring that children are made visible at an early stage in their parent's contact with the correctional system.

\section{Responding to Children at Parental Arrest}

While children's direct connection to the adult criminal justice system has received little specific attention, there has been some, albeit limited, focus on the circumstances surrounding parental arrest. Arrest has been investigated and found to be problematic due to the number of children present when parents are arrested as well as to the resultant trauma experienced by those children. ${ }^{25}$ Limited Australian data exist, however, on children's presence at, or involvement in, parental arrest. It is important to note here that the process of parental arrest also brings with it immediate practical consequences: the removal of that adult from their caring role, even for a short period of time. Although it would seem that only a small percentage of those who are arrested are immediately remanded into custody, ${ }^{26}$ the presence of children or the arrestee's responsibility for dependent children remains an issue which requires attention. For example, the decision to arrest and remove a parent has implications for children, who may then be in need of protection because of having no carer.

One of the very few studies which have investigated the specific responses of law enforcement agencies and child welfare organisations at parental arrest was conducted in California by Nieto. ${ }^{27}$ The findings

24 Ibid, 41.

25 D Dallaire and L Wilson, 'The Relation of Exposure to Parental Criminal Activity, Arrest, and Sentencing to Children's Maladjustment' (2010) 19(4) Journal of Child and Family Studies 404.

26 This data is not directly available, but can be extrapolated from a number of sources: The Victorian Law Reform Commission (2005) <http://www. lawreform.vic.gov.au/sites/default/files/Bail_Consultation_Paper_Final.pdf > indicates that some 26,000 arrested individuals were bailed by Victoria Police in 2005. At around the same time, 4862 people were received into Victoria's prisons (Victorian Department of Justice, 2007, <http://assets.justice.vic.gov. $\mathrm{au} /$ corrections/resources/baff3ae3-8f85-435d-a090-bc5eea31d5f9/statistical_ profile_victorian_prison_system_2001-02_to_2005-06small.pdf $>$ ). The NSW Law Reform Commission 2012 (cited in David Brown, 'Looking Behind the Increase in Custodial Remand Populations' (2013) 2(2) International Journal for Crime, Justice and Social Democracy, 80 , suggests that around $72 \%$ of prison receptions are those being remanded into custody. On this basis, it can be estimated that approximately $13 \%$ of individuals arrested are remanded into custody.

27 Marcus Nieto, In Danger of Falling through the Cracks: Children of Arrested Parents (California Research Bureau, 2002). 
indicate clear gaps in responses to children. Less than half of the law enforcement officers who participated advised that they would enquire about the care of any child or children present at the arrest of their parent parents. Where children were not present, only $13 \%$ of respondents state that they would enquire about children. As this data illustrate, children of offenders were not routinely considered in day-to-day policing practice. When evaluating how officers respond to children, Nieto describes a reliance on individual 'instincts'. For example, individual officers may make decisions about such issues as the care and placement of a child with no further oversight, and most do this with no procedures in place to assess carer suitability. The study highlights a number of issues of concern: the lack of awareness of parenting status/caring responsibilities of individuals being arrested; the lack of police policy around responding to children whose parents were being arrested; the absence of formal protocols between police and child protective services about these children; and poor communication between these agencies. It was concluded that these children are effectively 'falling through the cracks' because there is no attention to them during their parents' contact with the criminal justice system.

Subsequent to that study, there have been some promising strategies implemented at parental arrest in the US, aimed at improving responses to children and reducing trauma. Puddefoot and Foster ${ }^{28}$ describe the development of formal protocols in two Californian jurisdictions for responding at all arrests where children are present; these protocols include the requirement that arresting officers ask about children, and document this, when arresting an adult. These developments are part of broader work in these areas, including the co-location of Social Workers in police stations for consultation and assistance with children. Similar cross-disciplinary work is described in the New Haven Child DevelopmentCommunity Policing program in Connecticut, a now 20-year partnership between New Haven City, Police and Yale Child Study Centre. This project provides education about children and child centred practice to police and is a 24-hour consultation service; it requires police to document on the arrest sheet that they enquired about children; with progress and information sharing maintained via a weekly program meeting.

On a smaller scale in Australia, Victoria Police have recently expanded their trial of SupportLink, a computer-assisted single referral gateway. ${ }^{29}$ This allows the police to make service referrals for people they come into contact with, including family members and children, when arresting a parent. A formal evaluation of the trial is pending.

Changes in recent years now give some direction to Victoria Police officers about responding to children when arresting parents. ${ }^{30}$ Victoria Police have a protocol with the Department of Human Services (DHS)

$28 \quad$ G Puddefoot and LK Foster, Keeping Children Safe When Their Parents Are Arrested: Local Approaches That Work (California Research Bureau, 2007).

29 SupportLink, Supportlink (2013) National Police Referral and Diversion Framework <http://www.supportlink.com.au/default.aspx>.

30 Victoria Police, Victoria Police Manual (Victoria Police, 2010). 
- Child Protection, ${ }^{31}$ the lead agency for safeguarding children. This protocol provides some general guidance to officers about responding to children of parents in contact with the criminal justice system: officers must consider making a report to Child Protection if they believe that a child is at risk and in need of protection due to a range of circumstances including abandonment or parental incapacitation. It is noted that this 'may include situations where a primary carer of dependent children is in custody and incapable of caring for their child during this period and there is no other suitable person willing or able to care for the child'. ${ }^{32}$ While parental arrest is not specifically addressed, arguably this could be seen to lead to parental incapacitation. As it stands, however, what being incapacitated entails, or what makes a person suitable to care for a child are open to interpretation. In NSW, the Police Force Handbook outlines more specific procedures for officers who are caring for a child or children as a result of their parent's arrest, including attending to their basic and emotional support needs. ${ }^{33}$ Police must make 'all reasonable attempts' to place the child with another parent, relative, guardian or 'other approved person'. ${ }^{34}$ Similar to Victoria, in the absence of an approved person, police are required to contact the Department of Community Services (DoCS). While it acknowledges a police duty to respond to children, this Handbook also does not offer any guidance to officers as to who a suitable or approved person might be, nor does it make any reference to how such a decision would come about.

In 2010 in Washington a new sentencing option was introduced to respond to parents and children. The Family and Offender Sentencing Alternative (FOSA) targets parents of dependent children, who are found guilty of non-violent offences. ${ }^{35}$ Essentially it allows these parents, who must meet other criteria, to serve a 12 -month period of community custody - with conditions and regular monitoring by the court - as an alternative to imprisonment. Although it is argued to be showing benefits in terms of recidivism trends and successful completion of orders, there has been no formal evaluation to date. ${ }^{36}$

Despite this promising initiative, little is known formally about children beyond the point of parental arrest; at a parents' sentencing (in a more 'traditional' court setting), at the point of imprisonment or at post-release.

31 Department of Human Services, Protecting Children. Protocol between Department of Human Services Child Protection and Victoria Police (2012) <http://www. dhs.vic.gov.au/_data/assets/pdf_file/0019/442603/Protecting-Children-CP-andVicPol-protocol-2012.pdf>.

32 Ibid, 11.

33 NSW Police Force, NSW Police Force Handbook (NSW Police Force, 2013).

34 Ibid, 31.

35 Department of Corrections Washington State, Alternatives to Total Confinement for Some Parents of Minor Children (2014) <http://www.doc.wa.gov/community/ fosa/>.

36 Susie Leavell, Promising Outcomes for a Parenting Sentencing Alternative (2013) < http://www.vera.org/blog/promising-outcomes-parenting-sentencingalternative $>$. 
Related research in the Victorian Children's Court investigated sentencing processes, finding that without guidelines, magistrates tend to rely on personal experiences to inform decision-making. ${ }^{37}$ How such discretion plays out in the adult court system when sentencing parents with dependent children, is relatively unknown. Children's general invisibility during a parent's journey through the processes of arrest, sentencing and entering prison is, however, regularly noted. ${ }^{38}$

\section{Children: Indirect Recipients of Adult Justice}

From the instigation of research in this area, there has been some interest in the formal processes or systems which children and families have to engage with when a parent is facing imprisonment. This focus was first evident in the seminal work by Zalba who profiled the experiences of 124 imprisoned mothers and their children in California. ${ }^{39}$ Of concern from these early days was the lack of formal support, accessed or offered, for families, despite almost half of these children needing to move from home and almost one-in-four children experiencing behavioural problems. This study established three concerning and continuing trends: the social isolation of families involved with the criminal justice and prison systems; the poor linkages families have with formal support services; and the limited attention given to arranging the care of dependent children. The consequence of this limited attention has been described as the "haphazard' placement of children. ${ }^{40}$ Such ad hoc and informal care arrangements for children have been found in subsequent research. ${ }^{41}$ Later findings indicate that parents often feel they have no time to arrange care ${ }^{42}$ or feel unprepared for prison; ${ }^{43}$ at times this has been linked to a perception of

37 Rosemary Sheehan, Magistrates' Decision-Making in the Children Protection Cases (Ashgate, 2001).

38 See, eg, Judith Brink, 'You Don't See Us Doin' Time' (2003) 6(4) Contemporary Justice Review 393.

39 Serapio Zalba, Women Prisoners and Their Families (State of California Department of Social Welfare, Department of Corrections, 1964).

40 Ibid, 63.

41 See also B Hounslow, A Stephenson, J Stewart and J Crancher, Children of Imprisoned Parents (NSW Department of Youth and Community Services, 1982); Karen Healy, Denise Foley and Karen Walsh, Parents in Prison and Their Families: Everyone's Business and No-One’s Concern (Catholic Prisons Ministry, 2000).

42 D Gursansky, J Harvey, B McGrath and B O'Brien, Who's Minding the Kids? ... Developing Coordinated Services for Children Whose Mothers Are Imprisoned (Social Policy Research Group, University of South Australia, 1998); Alison Cunningham and Linda Baker, Waiting for Mommy: Giving a Voice to the Hidden Victims of Imprisonment (Centre for Children and Families in the Justice System, 2003).

43 William H Sack, J Seidler and S Thomas, 'The Children of Imprisoned Parents: A Psychosocial Exploration' (1976) 46(4) American Journal of Orthopsychiatry 618; Hounslow, above n 41; Healy, above n 41. 
inadequate communication with legal representatives. ${ }^{44}$ It has also been suggested that women facing imprisonment have fewer resources to draw on, and when combined with hastily made plans this may result in inappropriate placement. ${ }^{45}$ Beyond these general suggestions, little is known about what leads to such poor arrangements for children, what outcomes exist for children, or what could be done to improve this situation for children and families.

An exploratory study in Victoria specifically examined how care was arranged for 20 adolescent children whose mothers were imprisoned. ${ }^{46}$ Findings reveal that children's lives were more predictable and stable when secure care plans were in place. Although separated from their mothers, the immediate impact on children was minimised as children knew where they would be living for the duration of the imprisonment and were aware of their mother's location and when they could visit. Children also had the support of a carer, a sense of continuity, and were not simply left waiting. For those children who were living with their mother prior to prison and who had no secure arrangements in place, the initial response was a range of negative emotions: feeling let down, angry, distrustful, confused and anxious. ${ }^{47}$ What is of considerable interest is that these responses have been identified in previous research as the consequences of maternal incarceration more broadly. ${ }^{48}$ What these findings question is whether attention to children's care - and the provision of secure care, with its resultant stability and predictability - can mediate against these reactions. ${ }^{49}$ More formal oversight may address the issue of quality of care children receive from informal, and largely unsupported, carers. ${ }^{50}$ While knowledge in this area is in a developmental stage, knowledge from related areas supports the need for specific attention to children and

44 Fiona Begg, 2002 Serving Time on the Outside: A Survey of Visitors to Correctional Centres in the Wacol Region, Queensland (Queensland, Australian Community Safety and Research Organisation Incorporated (ACRO), 2002); Sack et al, above n 43.

45 Sandra Enos, Mothering from the Inside. Parenting in a Women's Prison (State University of New York Press, 2001); Healy, above n 41.

46 Catherine Flynn, 'Mothers Facing Imprisonment: Arranging Care for Their Adolescent Children.(Report)' (2013) 23(1) Women \& Criminal Justice 43.

47 Flynn, above $\mathrm{n} 8$.

48 Zelma W Henriques, Imprisoned Mothers and Their Children. A Descriptive and Analytical Study (University Press of America, 1982); Baunach, above n 5; Barbara Bloom and David Steinhart, Why Punish the Children? A Reappraisal of the Children of Incarcerated Mothers in America (National Council on Crime and Delinquency, 1993); Diane Caddle and Debbie Crisp, 'Mothers in Prison. Home Office Research Findings No 38' (Research and Statistics Directorate, 1997); Nola Tudball, Doing It Hard: A Study of the Needs of Children and Families of Prisoners in Victoria (Victorian Association for the Care and Resettlement of Offenders, 2000).

49 Flynn, above n 8; above n 46.

50 James M Gaudin, Jr and Richard Sutphen, 'Foster Care vs Extended Family Care for Children of Incarcerated Mothers' (1993) 19(3) Journal of Offender Rehabilitation 129. 
clear care plans when separated from their parents. ${ }^{51}$ Care planning is a much used term across many fields of health and welfare practice with varied foci, however, some intrinsic principles remain. Care planning, in the current research, is indicated where there is complexity of health and/ or social needs, where there is a need to communicate and work across multiple systems and/or professions, and where transitions need to be managed and progress monitored. As noted above, Australian/Victorian adult mental health services have made considerable shifts towards being child centred in recent years, incorporating care planning for children into their practice. Some of these ideas may have relevance to families negotiating the adult criminal justice system.

\section{E Caring for Children whose Parents are in Contact with Mental Health Services}

Although there are clear ideological differences between the adult criminal justice and mental health systems, children of parents with a mental illness (COPMI) share many characteristics of children of imprisoned parents. These include shared shame, stigma, poor mental health outcomes, antisocial behaviour, abrupt separation from parent due to institutionalisation, and limited access to services. ${ }^{52}$ Yet the service provision and advocacy for these equally vulnerable groups is vastly different.

Over the past decade, an increased awareness of COPMI has ensured that a number of services, interventions and programs have been developed to meet the needs of this group. One of these strategies includes an extension of the individual case management model to encompass family care plans. ${ }^{53}$ Developed as an outcome of consultations with relevant mental health workers, parents, children and extended family members, these plans incorporate both crisis planning (ie for relapse and hospitalisation) and care planning (relevant short and long term family goals) components. ${ }^{54}$ The aim of such care plans is to aid empowerment, enhance the family's capacity to manage during a crisis, reduce stress, minimise disruption to the family and to ensure that other crises are averted, such as children being placed into out-of-home care or siblings being separated. For family care plans to be successful, all key stakeholders - including relevant workers, parents, children and extended family members - must

51 Richard Kagan, Rebuilding Attachments with Traumatized Children. Healing from Losses, Violence, Abuse and Neglect (The Haworth Maltreatment and Trauma Press, 2004).

52 Marilyn C Moses, 'Children of the Incarcerated Must Be Studied, and Responded to, Comprehensively' (2010) 72(3) Corrections Today 58.

53 AE Reupert, KT Green and DJ Maybery, 'Care Plans for Families Affected by Parental Mental Illness' (2008) 89(1) Fam Soc 39; A Reupert and J Maybery, 'Don't Forget the Kids: Working with Families Affected by Parental Mental Illness' in Elizabeth Moore (ed), Case Management for Community Practice (Oxford University Press, 2009) 346.

54 Reupert et al, above n 53. 
be included within the discussion. This ensures that roles and associated responsibilities are discussed, clarified and negotiated..$^{55}$

There has been little to no research evaluating the effectiveness of family care plans. ${ }^{56}$ Despite this, family care plans within the mental health system may have some relevance for the criminal justice system as both groups of children will experience separation from the parent due to institutionalisation, separations may be abrupt and unplanned, and families typically experience a range of other difficulties. ${ }^{57}$ Appropriate coordinated care planning may be one way to manage the challenging and immediate circumstances experienced by these two groups of children, and to perhaps minimise the negative effects of parental incarceration. As noted earlier, one clear challenge to implementing an approach of this type (with children whose parent/carer is facing prison) is finding common ground between the systems involved, as each has distinctive underlying principles. Subsequently, it would also be challenging to identify who amongst the current 'players' would be willing and able to take a lead role on such an initiative. Yet any shifts in practice to become more responsive to children will require more than one organisation, and a cross-government approach. ${ }^{58}$

The current study subsequently sought a broad focus and widely sourced data, describing the processes of arrest, sentencing, imprisonment and community re-entry: to document what currently occurs in Victoria and NSW in relation to decision-making and meeting the care needs of children whose primary carers experience imprisonment.

\section{Methodology}

As part of an Australian Research Council (ARC) ${ }^{59}$ funded Linkage project this overall study sought to build Australian knowledge in this area, by describing the current care planning practices and experiences for children when their primary carer is incarcerated, in the Australian states of New South Wales (NSW) and Victoria. To meet this need, data were sought from multiple primary and secondary sources. Primary sources included 124 professional stakeholders from a range of sectors in direct contact with children and families of prisoners: magistracy, police, prisons, child protection, foster care and education; it also included representation from the non-government sector and community and government

$55 \quad$ Ibid.

56 Ibid.

57 Moses, above n 52.

58 Abram \& Linhorst, above n 23.

59 ARC Linkage Project Number LP110100084, The Impact of Incarceration on Children's Care: A Strategic Framework for Good Care Planning, 2011-2014. This study was conducted with the support of key partner organisations: Department of Justice, Victoria, Department of Human Services Victoria, Commission for Children and Young People, Victorian Association for the Care and Resettlement of Offenders, Prison Fellowship and SHINE for Kids. 
interest groups. Primary data was also gathered from 151 primary carer parents and a smaller group of carers and children, ${ }^{60}$ with data being sought during imprisonment and six months subsequent. This primary material is augmented by secondary data, on children and families, from government and non-government partners.

For the purposes of this paper, we focus on the data provided by professional stakeholders, centring on the processes leading up to imprisonment. As there is limited formalised knowledge of the experience of professionals in responding to children whose primary carer has been incarcerated, an exploratory approach, relying on a non-probability sampling strategy, was used. ${ }^{61}$ One of the main objectives of the study is to provide new insights on the experiences of this cohort.

A maximum variation sampling strategy, ${ }^{62}$ purposefully selecting a wide range of professions and/or areas of practice from across the arrestsentencing-imprisonment journey, and including participants from urban and rural areas, sought to generate a sample that represented the broadest group of participants possible, improving transferability of findings. Given the limited existing data about how children are responded to when their parents are in contact with the criminal justice system, with no existing research in Australia from a service-provider point of view, the intent of this approach was to '[capture] and [describe] the central themes that cut across a great deal of variation'. ${ }^{63}$ This approach was supplemented by snowball sampling, whereby participants recommended the study to other colleagues who they were aware had practice experience with this client group.

The current paucity of knowledge also led to the use of a semi-structured interview/focus group schedule for data collection. This schedule focused on five core areas: the organisational perspective on children of prisoners; organisational expectations of responding to these children; current processes for responding; professional experiences of working with these children; and suggestions for improvements. This approach allowed for comparison across stakeholder groups and states in the key areas of investigation, but also provided sufficient scope to allow for participants to shape the discussion, introduce new or unanticipated ideas, and capture the complexity of individual experiences and contexts.

60 This study defines as primary carers those parents/carers whose imprisonment precipitated either: a new carer (relative, friend, or associate) taking over the care of the child or children in their own home; the child or children being moved to a new house to live with a different carer; or the child or children being left with no carer. A total of 38 mothers and 39 fathers participated in initial interviews in Victoria; with 53 mothers and 21 fathers in NSW; and 27 carers and five children also contributed data. At the time of publication, follow up interviews, were being conducted with primary carers.

61 Allen Rubin and Earl R Babbie, Research Methods for Social Work (Thomson Brooks/Cole, 2008).

62 MQ Patton, Qualitative Research \& Evaluation Methods (Sage Publications, 3rd ed, 2002).

63 Ibid, 234-235. 
Ethical oversight of the project was complex, with a total of nine Human Research Ethics Committees (HREC) or Research Coordinating Committees (RCC) reviewing and approving the project. ${ }^{64}$ Data gathering occurred during the period October 2011 to May 2012, followed by a later period with education staff from May - August 2013 in Victoria and October - February 2014 in NSW. In Victoria, data gathering with professional stakeholders included the capital city, Melbourne, as well as one regional area. Given the much larger geographical area of NSW, participation by individuals in a range of regional, rural and remote settings was facilitated by implementing a telephone interviewing strategy. Face-to-face data collection was limited to two key sites: again the capital city's (Sydney) metropolitan area and one regional area located in Northern NSW.

The majority of the data gathering sessions were audio recorded; where this was not possible, for example, due to security constraints in prisons, note taking was employed to record the data. In Victoria a total of 15 focus groups and four individual interviews were conducted over the data gathering period. In NSW there was a total of 29 individual interviews and six focus groups. The predominance of individual interviews in NSW reflects an effort to accommodate the needs of some professionals with considerable time constraints as well as their geographical location. All audio material was transcribed. Once the bulk of the interviews and focus groups were completed, all researchers who were involved in data gathering had input into the identification of 13 key themes related to the research topic. These were refined through discussion until five major themes in line with answering the research question were agreed upon, as is appropriate with research of an exploratory nature..$^{65}$ One researcher then had primary responsibility for coding transcripts via NVivo10 data analysis software. Multiple coding of a selection of transcripts was also undertaken by three members of the research team to check inter-rater reliability of the coded themes. Analysis of this qualitative data took an enumerative approach, where the repetition of words and ideas indicates importance. ${ }^{66}$

\section{FIndings}

To discuss current responses to children of parents facing prison across Victoria and NSW, three core events leading up to a term of imprisonment were focused on: arrest, sentencing and the point of imprisonment. Based on an enumerative approach, analysis of the data indicates that there were four core challenges raised by stakeholders across both states

64 These consisted of Monash University HREC, Victorian Department of Justice and its NSW counterpart Corrective Services, Department of Human Services Victoria and Family and Community Services in NSW, Police in both states, and the Department of Education and Early Childhood Development in Victoria, as well as the Department of Education and Communities in NSW.

65 Carol Grbich, Qualitative Data Analysis: an Introduction (SAGE, 2007).

66 Alan Bryman, Social Research Methods (Oxford University Press, 3rd ed, 2012). 
which influenced their responses to families as their parent or parents move through the criminal justice process. As indicated in Table 1 below, these include: 'lack of formal protocols'; 'displaced responsibility' - where professionals look to other organisations as being responsible for children; 'limited information sharing'; and 'worker knowledge and skills'. While additional issues were raised that were both similar across states, and state specific (see Table 1), the current focus is on the most prominent themes shared by both states as this allows for an in-depth analysis of these key ideas. It must be noted that while 'remote locations' and 'Indigenous communities' were issues raised predominantly by NSW stakeholders, this may have been specific to the NSW sample, as there were a number of workers based in rural settings. 'Worker knowledge and skills' was a theme that underpinned other core themes: analysis of this data has thus been incorporated into those discussions. The following findings present a summary of the most prominent ideas to emerge in each of these core themes, including quotes from the study participants to highlight commonly shared ideas.

Table 1 Themes identified by both States across arrest, sentencing and imprisonment

\begin{tabular}{|l|l|l|l|}
\hline \multirow{4}{*}{$\begin{array}{l}\text { Core themes } \\
\text { Arrest }\end{array}$} & \multicolumn{3}{|c|}{$\begin{array}{l}\text { Sentencing } \\
\text { Lack of guidelines and protocols } \\
\text { Worker knowledge and skills } \\
\text { Displaced responsibility } \\
\text { Lack of information sharing }\end{array}$} \\
\hline \multirow{3}{*}{$\begin{array}{l}\text { Additional } \\
\text { themes }\end{array}$} & $\begin{array}{l}\text { Complex families } \\
\text { Lack of resources } \\
\text { Role of extended families } \\
\text { Indigenous communities (NSW } \\
\text { only) } \\
\text { Remote locations (NSW only) }\end{array}$ & & $\begin{array}{l}\text { Poor data on children } \\
\text { No follow up support } \\
\text { for families }\end{array}$ \\
\hline
\end{tabular}

\section{A Lack of Protocols and Guidelines}

It was common for stakeholders in NSW and Victoria to describe the lack of formal protocols and mechanisms for responding to children whose parents were facing imprisonment:

A protocol could be sitting with our regional director or our CEO also, that's never ever drifted down, like lots of other protocols. (Foster care, Vic)

[There is no protocol] that I am aware of ... I usually just find out or parent tells me. Disorganised and time consuming. Is this benefiting the child? (Foster care, NSW)

Don't know, haven't come across it if there is. (Child Protection, NSW)

Although this was described as problematic at all key decision-making/ transition points, this gap was noted as particularly evident at arrest and sentencing - crisis points that require clear guidance for all involved. 
When describing arrest processes, data reveal limited understanding by Victorian Police of any broader obligations police may have to consider the protection of the child when arresting their primary carer:

There's no clear steps or guidelines in place. (Police, Vic)

I don't know if it is a policy or guidelines. (Police, Vic)

Similarly, police participants from NSW did not indicate knowledge about required responses to children in arrest situations, despite the NSW Police Force Handbook providing guidelines for such responses:

But there's no real set. You kind of just gauge it. (Police, NSW)

As these examples illustrate, police participants were unaware of any formal organisational responsibilities to contribute to the protection of children, in situations arising from parental arrest. Interestingly, responses do indicate an informal expectation that at arrest, police officers will enquire about children. This is constructed, however, as an unwritten duty of care, a part of their overall community responsibility:

We've got to ensure that they [children] are safe. That's our role, to make sure that they're safe and that they're looked after. I think it's part of our duty, not to babysit, but we've still got to look after the kids - we've got to look after the offenders. (Police, Vic)

I would expect my members to make enquiries about is there another parent or a carer responsible for those children. (Police, Vic)

You've certainly got a duty of care, you still have to do the immediate things first and try to prioritise. (Police, NSW)

It is unclear, however, how worker knowledge and informal expectations are transmitted.

While the key role played by supervisors in providing back-up, support and advice to new recruits was described by police participants, what guidance they provided, and what was prioritised, were quite dependent on the knowledge and skills of the individual supervisor as well as on the culture of the police station. One police participant spoke of a very early positive learning experience with a senior member of staff, which remained influential in their practice a number of years later:

He was an ex-school teacher and you could tell he was one of those strict disciplinarian teachers. He was a terrific bloke. But he said to me once, and it stuck with me, he said, 'I never, ever, ever lecture anyone [being arrested] in front of their kids'. He was a dad. He had a couple of kids or whatever - and I've never done it as a result of - it's just some things, you know. So it's not just the physical thing. They don't need to be lectured, or told off or demeaned in front of children as well. (Police, Vic)

The individual nature of decision-making was, thus, highlighted in the data about police practice and reinforces Nieto's findings that officers rely on instinct when responding to children. ${ }^{67}$ For example, it is understood that how, or if, children are considered when arresting a parent is influenced by the individual officer, their level of experience, and the current focus of their education and training: 
[Y]ou might get a different response. If I put in a trainee that had six months experience that had to arrest, you don't have the experience ... 'my job is to arrest the person and charge them with theft'. They want to make sure they fill out the right forms, you know? That's because at the academy, that's what they're taught. (Police, Vic)

I think so given their experience because some officers don't even have - like they're 17 or 18 or however old they are, they might be very young and they might not have that knowledge. (Police, NSW)

It's such a circumstantial thing, what I consider to be high risk may not be high risk to another officer ... So it's quite subjective. (Police, NSW)

As noted earlier, without clear, formalised guidance, professionals rely on personal frameworks or experiences to shape their decision-making. ${ }^{68}$ For children of prisoners, these idiosyncratic responses can result in positive and responsive outcomes, or those that are quite the opposite. This is clearly the case when children's parents are being sentenced.

Although not seen to be direct participants in the adult criminal court, 'children' are, at times, factored into sentencing. In NSW, for example, the Crimes (Sentencing Procedure) Act 1999 includes the presence of children during an offence as an aggravating factor when sentencing. ${ }^{69}$ In this case, the effect of an offence on children is seen to be relevant. However, data relating to sentencing, and the likely impact of parental incarceration on children, suggests that in these instances the effects/consequences of offending on children are not seen to be relevant. Magistrate respondents clearly indicated that there is insufficient guidance for dealing with children when sentencing:

No, I don't think there's any systems. I've got no idea. I wouldn't have a clue. Here's the thing - I think the fact that we don't know is interesting in and of itself. (Magistrate, Vic)

If children are an issue they will bring in usually female police and or Family Community Services if the people are in custody. If they're not in custody the solicitor generally has the responsibility to deal with those issues if they become pertinent. [It is not a formal process] ... it's just the way we work. (Magistrate, NSW) NSW)

I would say it's a matter for the individual magistrate (Magistrate,

Variance seems an accepted and acceptable feature of usual court practice, with a clear awareness that decisions are influenced by a magistrate's gender, age and personal experiences. Subsequently, the extent to which hardship to children is, or should be, incorporated into sentencing decisions varied widely amongst magistrate participants, with no guidelines as to assessing or applying hardship. ${ }^{70}$ Some, who saw sentencing and the consequences of this more broadly, incorporated this as a core issue for consideration:

\footnotetext{
68 Ibid, Sheehan, above n 37.

69 Crimes (Sentencing Procedure) Act 1999 (Vic) Section 21A-aggravating and mitigating factors.

70 Crimes Act 1914 (Vic); Crimes Act (Sentencing Procedure) 1999 (Vic).
} 
Obviously, if you're incarcerating a primary carer, usually a woman with children, that's something that you take, I would take into account as a very significant factor, in making the decision whether or not to incarcerate, or whether there's some other alternative way of dealing with her offending. (Magistrate, Vic)

Others, however, maintained a focus solely on the individual and their crime:

I don't give any consideration [to a defendant's children] ... Generally when they committed the offence, they were a parent at the time; they disregarded and abrogated that responsibility, and it's not part of the sentencing option, it's not part of the principles. (Magistrate, NSW)

Given that magistrates operate with relative independence - relying on 'instinctive synthesis' - the implication for children of parents facing court is that there is no consistent or predictable outcome. Furthermore, the exclusion of children in guidelines relating to parental imprisonment only adds to the uncertainty and questions why some children are seen to be significant in sentencing processes and others are not.

\section{B Displaced Responsibility}

The current lack of guidelines for practice and protocols with regard to children can be seen to affect professionals' sense of responsibility toward these children, where no one group or organisation in either State is identified as the 'go-to' people. Hence, children all too easily fall through the gaps in services. This phenomenon, whereby there is a transfer of responsibility, was a key theme evident in the data and one that has been labelled 'displaced responsibility'.

As has been suggested previously in relation to COPMI, all relevant parties being invested and having a clear sense of their role and responsibility is vital for planning and any subsequent responses to be successful. ${ }^{71}$ Stakeholders acknowledged that joint responsibility was needed to plan and appropriately respond to children at arrest, sentencing, and imprisonment, for example:

I think there's a philosophical responsibility or a community responsibility that goes beyond any legal responsibilities. (Legal, Vic)

However, it was more common, at every stage of the trajectory, for professionals to displace that responsibility onto other organisations or to parents:

They don't want to put their hand up and say, 'That's our responsibility. We'll deal with it. 'They try and palm it off to someone else and there usually is no one else. (Police, NSW)

Everyone needs to work together ... a lot of passing the buck. Service providers call and say the family's [here], what is DoCS [child protective services] going to do? (Child Protection, NSW).

With no clear responsible body, it is often left to crisis or emergency services to intervene and take action. Police stakeholders felt that they 
were sometimes left 'holding the baby', usually without the resources required:

Yeah, quite often we bring kids to the [police] station, or at times we leave someone at the house. We had a four year old at the station for about 10 hours the other day because the father was involved in offending ... While the child is at the station ... usually the only person that can look after them is the watch-house keeper, who's also managing the phones, doing the front counter. There's just no-one else available, especially on weekends. (Police, Vic)

A lot of the onus just tends to be dumped on police. Like there's such a lot of work for us to do when we - because we're the first responders we're the ones that get lumped with doing everything. (Police, NSW)

Child protection workers expressed similar concerns:

The frustration is that we're the child protection workers, we're not the criminal justice workers, we're not the family support workers, we're not this, we're not the other, but the responsibility still all comes back onto us for everything. (Child Protection, Vic)

The lack of any clear protocols, as well as transfer of responsibility, thus results in ad hoc responses to children that are reactionary and indistinct; a situation that is compounded by the lack of interagency communication.

\section{Limited Information Sharing: 'One End of the Legal System Doesn't Talk to the Justice System' (NGO, Vic)}

Data reveal that there was a lack of commitment to sharing information between organisations involved in both NSW and Victoria with regard to children. It was common for participants to describe their organisation as lacking in information about the children and to see it as the responsibility of other individuals or groups they were in contact with to offer that information voluntarily:

[I]t's only if they raise it with us that they've left children unattended we'd be aware of it. (Police, Vic)

The lack of information shared with the school is a big problem because we're the ones who are picking up the pieces for the majority of the time ... but we're the ones who are kept in the dark the most. (Education, Vic)

We have the same issues when parents break up, some divorce happens and we don't find out for four weeks and the poor kids had this massive change in behavior and they're not sleeping or eating, they've been very ratty, fighting with their friends and been disruptive in class. We can manage that if we know, but it is very difficult to manage when we don't know. (Education, Vic)

Less commonly did individuals see it as necessary to seek out information about children. Where this occurred, it was sometimes perceived as being dependent on the professional involved:

I will ask, but this is just me. I will ask about children and I will ask about what the arrangements are. (Magistrate, Vic)

[I ask] the extra questions about the person's circumstances. We don't just sit there passively. (Magistrate, Vic) 
There was also a lack of agreement as to what information about children needs to be shared, when, how and with whom indicating a lack of attention to children. Furthermore, each organisation has its own focus and priorities, which are mutually exclusive:

[L]awyers have a job to do: to obviously protect their client's interest. You don't necessarily get all the information. (Magistrate, Vic)

Often one of the difficulties that I've experienced is that we're relying on the parent to tell us what the rules are. We don't know what the rules are with prisons and how that all works (Foster care, Vic)

Our (Child Protection) legislation says that you can give us any information that's relevant to the investigation in relation to the safety and wellbeing of a child. They [prisons] argue it's not relevant because this person is incarcerated. (Child Protection, Vic)

What this indicates, therefore, is a distinct gap in rhetoric and practice that focuses on children whose parents are facing imprisonment.

This can be seen at the point of imprisonment, where there was a lack of communication and appropriate sharing of information between prisons and outside agencies. Stakeholders indicated that there was a lot of time spent trying to acquire information or to locate people 'in the system':

We don't know who should be contacts for us in the Department of Corrective Services and this is difficult when working with the jails. When we have had people in jail we try and get the parents out of jail to say goodbye - things move slowly and there have been times where hospitals want to switch off life support - who to talk to in these situations is difficult and seems to differ between jails. (Child Protection, NSW)

So even just trying to keep track of some of the parents is really hard and it's hard for the children, to explain that to them and for them to be able to understand and accept that. (Foster care, Vic)

But DHS couldn't give us the information and there was no one that could actually provide the information because of the confidentiality and privacy issue so it was actually like solving a huge puzzle and when he finally got the information about which prison he was in and contact was made which the social worker did, they said 'oh no, he's actually been transferred somewhere else' (NGO, Vic)

Of particular concern was the time spent on remand; a factor exacerbated by the apparent lack of follow up with children and families:

I found the most difficult times to try and facilitate those relationships with the prisons is when the prisoners are still in that assessment so they're at [Melbourne Assessment Prison] or the remand centre so they're not really sure where they're going off to and it's just facilitating that. If you do facilitate something it all gets lost once they go to their other facility. (Child Protection, Vic)

I think it reinforces though the whole thing that each program doesn't actually have any recognition that this is a family and there are connections that need to be maintained that will be beneficial not only for the child but also to the person who's in prison. (NGO, Vic)

I guess it highlighted for me just how lacking support is for victims and families of inmates, like how justice systems focus primarily on the person who has offended, no resources really provided to the victim or to the family of the offender. (NGO, NSW) 
While there are protocols in place during the prison reception process for assessing individual prisoners, and general enquiries about a prisoner's parenting status are made at this point, this process is problematic for a number of reasons. Firstly, prisons are reliant on the prisoner voluntarily advising of the location, care arrangements and wellbeing of their children; secondly, prison participants indicated no knowledge of any formal processes in place to respond to problems disclosed in relation to children (again, there is reliance on the individual and informal interventions); and finally, data on children are currently not gathered in a way that is considered useful to outside agencies. Subsequently, there is very little accurate data captured about children whose parents are entering the prison system, and little knowledge about their outcomes. Overall, it would appear that the problems previously identified by imprisoned parents, including poor communication ${ }^{72}$ and limited time to attend to children, ${ }^{73}$ and the subsequently haphazard and informal nature of children's care, are mirrored in the responses of professionals.

\section{What is Working?}

The evidence presented clearly describes the challenges faced by children and families of prisoners and those working to assist them across the states of Victoria and NSW. It is important to also acknowledge and build on strategies which participants describe as helpful in working with these children and families. The provision of specifically targeted support services was seen as an area that was extremely beneficial to children whose parents are in prison. While acknowledging the need for a broad community response, it was seen as vital for these families and their children to have the benefit of access to specialised staff/organisations. More generally, it was mentioned by several stakeholders that the use of Community Consultative Committees ${ }^{74}$ (CCCs) in correctional centres across NSW are a useful way of initiating discussion and action on major issues as attendance is marked by key stakeholders (including police, councils, and Corrective Services). It was also noted by magistrates in both Victoria and NSW that strategies do currently exist for sharing ideas and maintaining open dialogue between courts and the community. One approach given considerable emphasis was 'Court Craft'. While these sessions take place intermittently, they are an opportunity for magistrates to observe how other magistrates operate and much is learned from these exchanges (such as terminology, management of specific problems that might arise in court, and multicultural issues). Both CCCs and 'Court Craft' are good examples of what can be achieved when there is investment

$72 \quad$ Sack et al, above n 43.

73 Gursansky et al, above n 42; Cunningham \& Baker, above n 42.

74 New South Wales Government Corrective Services NSW, Community Engagement <http://www.correctiveservices.nsw.gov.au/offender-management/ community-engagement>. 
from partners in an issue along with a commitment to communication, and where innovative strategies become embedded in usual practice.

Data outlining current best practice also highlight areas for further focus, primarily the need to pay attention to children throughout the process, underpinned by a shared sense of responsibility for the care and safety of children:

Yeah, the relationships are crucial, they really are. If we don't have that relationship with the prison I think the system - the service certainly wouldn't be what it is. (NGO, Vic)

It should be a village, as they say - it should be the village and it's not at all. (Child Protection, Vic)

And we can talk about police and what they do and what they don't and things like that until we're blue in the face. At the end of the day we've got to look at solutions, and ways we can assist the police. (NGO, NSW)

This suggests that if agencies work in a collaborative way when responding to children, building and maintaining relationships within, and between, organisations while adding to the effective strategies that already exist, children may indeed be responded to appropriately. Data indicates, however, that this is not occurring and, as a result, children remain invisible throughout the criminal justice system.

\section{Conclusion}

General research in the area of imprisonment has focused on intergenerational links in offending, the behavioural and emotional impact of imprisonment on children and describing who does the caring once a parent has gone to prison. Care planning, understood as a systemic approach to the immediate and longer term safety and care of children, has had almost no appeal to researchers in this area. One of the reasons there is little interest thus far may be due to the assumption that the criminal justice system, and the associated services that come with it, is an exclusively adult system that has little, or nothing, to do with children. Yet when children are recognised as a central aspect of service delivery along the imprisonment trajectory, the negative impacts of incarcerating their parents can be mediated, thus minimising the trauma and subsequent instability associated with imprisonment.

Children are as much the recipients, albeit indirectly, of 'justice' as the adults who are incarcerated. Recognition of dependent children as part of the adult service system is beginning to take hold across different locations ${ }^{75}$ and in services including mental health and alcohol and drug services in Australia, as noted earlier. Our evidence shows, however, that in relation to children whose parents are in prison, the focus is haphazard and relies heavily on individualised approaches and the strength of the

75 Hannah Roscoe, Hugh Constant and Shirley Ewart-Boyle, Families and Children's Services: Report 56 Think Child, Think Parent, Think Family: Final Evaluation Report (Social Care Institute for Excellence, 2012) <http://www.scie. org.uk/publications/reports/report56.pdf>. 
stakeholder's professional networks. Such an atomised approach is related to a lack of specific protocols or directions, poor communication amongst service providers, and a generalised sense that children are someone else's responsibility. For services to be effective they will need to: inquire about children; communicate with parents; record information on children; and share it with relevant parties. This, however, requires support and resources for the organisations involved.

In practical terms, this means generating holistic services with a "no wrong door ${ }^{76}$ policy at each stage of the prison trajectory, where potential clients could look for assistance if, and when, it is needed. At the same time, clients would be actively targeted by agencies offering support and assistance. This shift in focus would also require open channels of communication between agencies to ensure there is a common knowledge base to work from. Such a collaborative approach to care planning, where information and knowledge about children is shared, replicates findings by Abram and Linhorst which demand that linkages, between statutory and non-government-funded organisations, and between prison and community based services, be made. ${ }^{77}$ While recognising that such action will require a significant paradigm shift for some organisations, one only needs to look to other jurisdictions to see that this is possible. The development of the 'Think Family' framework in the United Kingdom is an example of one such initiative. ${ }^{78}$ Within this framework, action is being taken to implement cross-organisational staff training: to ensure staff consider the family situation of the client; to encourage and support staff to work with other agencies to meet the needs of the wider family, not just their client; to initiate information sharing to identify those at risk and provide them with support; and to prioritise the wellbeing of children within the family environment. There is no reason why such an approach could not be actioned in Victoria or NSW. This will go further towards ensuring children are seen as significant and central figures within the criminal justice system, who are responded to promptly, and adequately.

A specific focus on children at the point of arrest will ensure that parents have adequate time to arrange care for their children. While the relevant police manuals and protocols highlight several crucial factors that exist for officers when they come into contact with children, more direction is required to ensure children are adequately cared for and time spent at arrest is utilised. It is recommended that elements of the best practice models identified in the United States are incorporated into local processes, as well as into police training, where there is an emphasis on child-sensitive arrest procedures. This would see the implementation of formal protocols at the point of arrest that would require arresting officers to ask about children. ${ }^{79}$ It would also require arresting officers to document these interactions to allow for information sharing between key

$76 \quad$ Burns, above n 14.

77 Abram and Linhorst, above n 23.

78 Puddefoot, above n 28.

79 Ibid. 
agencies and consistency. Additional questions to ascertain and respond to the specific circumstances and needs of the person being arrested have already been successfully incorporated into the arrest process, such as the need to inquire about indigenous status and to contact the Victorian Aboriginal Legal Service if holding an Indigenous person in custody.

Clear guidance is also required for determining who is a suitable adult to care for children, as too much ambiguity currently exists. The researchers are aware that police officers have multiple responsibilities at the point of arrest: to arrest the person in a timely and safe manner and to ensure that correct process is followed and evidence obtained. The presence of children or the arrestee's responsibility for dependent children, however, remains an issue which requires attention, as the decision to arrest and remove a parent has clear implications for children, who may then be in need of protection. The formalisation of guidelines such as these, and the inclusion of these into police training, would ensure that procedures for dealing with, or enquiring about, children at the point of arrest are not reliant on the skills of the workers involved and can ensure that relevant external resources are brought to bear.

Clear child-focused protocols and guidelines would also need to be developed and made available to professionals working in the adult court system. It is not enough that protocols simply mention children. In order to be effective, guidance on decision-making in relation to sentencing is needed. One illustration of formalised guidelines in practice, and an alternative sentencing option, is seen in Washington's FOSA. These sentencing alternatives represent a formal recognition within sentencing policy that children are affected by parental imprisonment. Given the current findings, this type of approach has the potential to be extremely beneficial to affected children in Victoria and New South Wales and would be a bold move away from the increasingly punitive sentencing policies that have become popular today. To be all the more effective, these guidelines need to be supplemented by existing best practice initiatives, such as 'Court Craft,' that foster inter-agency communication. While respecting the individual skills and integrity of magistrates, having periodical 'Court Craft' sessions, along with formalised guidelines, would authenticate the systemic processes for responding to children and remove any ambiguity that exists around children and their place in the criminal justice system

The formalisation of child-focused practices and guidelines is also required at the point of imprisonment, as well as a systemic commitment to information sharing, to allow for efficient outcomes for children. At present, record keeping with regard to children is simplistic. It is recommended, therefore, that data on children is standardised and centralised for all agencies to access independently. In addition, clear questions about children and their care need to be raised and documented at the point of imprisonment. Implementing a memorandum of understanding between Child Protection and the prison system is one way that follow up procedures could be formalised. This will ensure there is follow up for children whose whereabouts is unknown, or for those whose safety is questioned. 
This would also be an ideal opportunity to incorporate information sharing at the point of arrest for incarcerated parents, where information about supports and services for family are passed on.

In sum, a cooperative approach between all parties involved would have to prevail to ensure that children, their families and their parents, are provided with services they need. Such a shift goes counter to the specialised and often compartmentalised approach to service delivery that has been so pervasive in recent times. Yet evidence points to the need for integrated services and child-centred policies.

By taking a child-focused approach to dealing with the impact of incarceration on the family, where secure care plans for children are implemented from the point of arrest, the shortcomings that have become commonplace today can be minimised. This will require recognition from government departments, state-run providers, and NGOs that planning for the care of children whose parents are faced with incarceration is a shared responsibility. The development of child-centred guidelines or policies that involve all relevant parties would be a positive step forward. Current cross-government coordinating boards would seem well placed to lead the way with this pivotal phase. The inclusion of children impacted by parental imprisonment into these guidelines would ensure official oversight at the government level and would formally recognise these children as a vulnerable group in need of support. Taking a 'holistic approach' to service delivery, placing the client and the family at the centre of service delivery, ${ }^{80}$ will ensure 'vulnerable' groups are prioritised: this is the ideal time to take action by formalising responses to children impacted by parental imprisonment.

80 These principles are fundamental parts of both the Children's Services Coordination Board and the Community Sector Reform Council. Refer to Department of Human Services, Service Sector Reform: A Roadmap for Community and Human Services Reform Report (2013) <http://www.dhs.vic. gov.au/about-the-department/documents-and-resources/reports-publications/ service-sector-reform-a-roadmap-for-community-and-human-service>. 